\title{
Impairment of Bolus Transport or Lingual Motion
}

National Cancer Institute

\section{Source}

National Cancer Institute. Impairment of Bolus Transport or Lingual Motion. NCI

Thesaurus. Code C127202.

An observation of an individual's bolus transport and lingual motion during swallowing. 